\title{
Beyond individual behaviour change: the role of power, knowledge and strategy in tackling climate change
}

\author{
Anneleen Kenis ${ }^{1}$ and Erik Mathijs \\ Earth and Environmental Sciences, KU Leuven, Leuven, Belgium
}

\section{This is a draft (pre-print) version of an article which is published in 'Environmental \\ Education research'. Check the following website for the final, published version: http://www.tandfonline.com/doi/citedby/10.1080/13504622.2011.576315\#tabModule}

\begin{abstract}
Individual behaviour change is fast becoming a kind of 'holy grail' to tackle climate change, in environmental policy, the environmental movement and academic literature. This is contested by those who claim that social structures are the main problem and who advocate collective social action. The objective of the research presented in this paper is to better understand why environmentally concerned citizens choose one of these two types of engagement. Our focus is on the role of experiences of and/or convictions about power in shaping this choice. Within the framework of an explorative qualitative study, we engaged in in-depth interviews with twelve young environmentally concerned citizens. On this basis, five main findings are elaborated. Firstly, powerlessness is shown to be a crucial experience, whatever the respondents' engagement. Secondly, 'strategy scepticism' seems to be a more important obstacle for engagement than 'climate scepticism'. Thirdly, many respondents express significant resistance towards being 'conditioned' by awareness raising campaigns. Fourthly, a 'gap' is observed between respondents' analysis and their strategy proposals. Finally, we underscore another important gap between concrete and abstract levels in respondents' discourses. All these findings disclose paradoxical aspects of the role of power in shaping concerned citizens' engaged choices.
\end{abstract}

Keywords: Pro-environmental behaviour; Environmental Activism; Power; Governmentality; Gramsci; Knowledge; Strategy

\footnotetext{
${ }^{1}$ Corresponding author. Email: Anneleen.Kenis@ees.kuleuven.be; $\underline{\text { Anneleen.kenis@ @otmail.com }}$
} 


\section{Introduction}

Individual behaviour change is fast becoming a kind of "holy grail" in environmental policy today (e.g., Jackson 2005, 121; Stevenson and Keehn 2006; DEFRA 2008). Its goal is to "encourage, motivate and facilitate more sustainable attitudes, behaviours and lifestyles" (Jackson 2005, iii). These attitudes involve "more sustainable patterns of consumption, covering the purchase, use and disposal of goods and services" (13). A broad spectrum of measures has been developed to reach this goal: from education programmes, such as awareness raising campaigns, to economic rewards. With the help of a whole range of incentives, policymakers try to steer individual (consumer) behaviour in the intended 'environmentally friendly' direction. Until recently, there has been an increasing tendency in this approach to use non-rational means to influence behaviour (e.g., McKenzie-Mohr and Smith 1999; Heimlich and Ardoin 2008). Tim Jackson (2005, vi) underlines for example "the need for policy to [...] attempt to affect individual behaviours (and behavioural antecedents) directly". This means, for example, using role models, social pressure or connoting the desired behaviour to positive feelings of freedom, friendship or sex, as is also done in the advertisement industry.

The focus on education for individual behaviour change is also present in the strategies that a number of conventional environmental movements put forward today. Environmental movements often make it the cornerstone of their campaigns to convince people to take the bicycle instead of the car, to buy organic food from nearby or to avoid overpackaged cookies, tooth brushes or pineapples. Of course, there are other strategies. Many environmentally concerned citizens point to the way society is organised (the transport infrastructure, the organisation of cities or the profit-driven market economy) and engage in collective social actions for what they call 'structural change'. These can take the form of 
petitions, demonstrations or blockades, aimed at protecting rain forests, fighting against traffic or banning genetically modified organisms (e.g., Wall 1999; Griggs and Howarth 2000; Doherty, Plows, and Wall 2003; Rootes 2009).

But why do people choose for one type of engagement rather than another? Our research started from the observation that we have little knowledge of people's motives in making this choice. Moreover, the basic assumptions of such engaged choices often remain implicit. Fundamentally different visions of the root causes of environmental destruction, of possible solutions and even of human beings and society seem to be playing a role.

In this study we started from the hypothesis that a crucial question underlying this dilemma is that of power: who has power and how can one exert power and thus realise change in a sustainable direction? That this notion of power is important is already obvious if one looks at some of the main slogans environmental movements use to further their case.

Between 'You've got the power to choose' as a conscious consumer and 'Reclaim Power' through collective action, the analysis of power differs, but the realisation that power matters does not. ${ }^{1}$ We think that a focus on power can help to explore why people choose a particular type of engagement rather than another, and that this can constitute a fruitful contribution in current debates in environmental policy, the ecological movement and, as we will argue, also among scholars.

In section two, we will compare the main theses of the literature on education for individual behaviour change with those of education for collective social action. Section three introduces our research objectives and the design of our empirical research. In the fourth section, the research findings are demonstrated and discussed. In the final section, we formulate some general conclusions. 


\section{Literature review}

In the academic literature, a similar division can be found as the one described above. A big part of this literature focuses on education for 'pro-environmental behaviour', which often actually means education for individual behaviour change (e.g., Rickinson 2001; Kollmuss and Agyeman 2002; Bamberg and Möser 2007; Heimlich and Ardoin 2008). This research often starts from an observed 'gap' between 'knowledge' and 'action', and has practical aims. It examines the factors that explain why and when people commit themselves to changing their individual behaviour, in order to be better able to influence people in this direction. Contrary to this approach, there exists literature which starts from a totally different point of view. It also studies people's motives for taking action and develops education programmes to stimulate this, but it defines action very differently, namely as a collective engagement to influence politics, policy or corporate management and to change social relations (e.g., Clair 2003; Kapoor 2003; Jensen 2004; Clover 2006; Malone 2006).

Inevitably, different visions on the root causes of environmental problems and their possible solutions, and on human beings and society, are playing a key role here. Firstly, while the individual behaviour change approach generally tends to conceive of the environmental issue in terms of the sum of individual decisions and choices, the collective social action approach stresses the role of social structures and systems in causing environmental problems (e.g., Courtenay-Hall and Rogers 2002; Jensen 2002; Clover 2003; Chawla and Cushing 2007). Secondly, while the first approach asks the question how people can be steered into a predetermined 'pro-environmental' direction in their capacity as consumers, the second approach rather stresses their status as citizens, embedded in collective agencies constituting the 'subject' of social change (e.g., Courtenay-Hall and Rogers 2002; Carlsson and Jensen 2006; Jensen and Schnack 2006). Thirdly, whereas the first approach promotes education that mainly focuses on positive-scientific knowledge of the nature and 
effects of the environmental problem and on knowledge about prescribed 'pro-environmental behaviour' strategies, the second recommends raising people's 'knowledge' in a broader sense, including for example the root causes of the environmental problem, visions on alternatives and a broad spectrum of strategies to realise them. In this broader sense, more than 'knowledge', narrowly conceived, is at stake (e.g., Clair 2003; Clover 2003; Jensen 2004). The aim of this second type of education is rather to enhance people's 'action competence', which requires more than mere knowledge (e.g., Jensen 2002; Jensen and Schnack 2006). Fourthly, the first approach tends to understand power as a psychological phenomenon. It stresses the importance of, for example, 'locus of control' and 'perceived behavioural control' (e.g., Kollmuss and Agyeman 2002; Jackson 2005), and tends to understand people's statements about experiences of powerlessness as expressions of their psychological barriers for engaging in individual behaviour change ${ }^{2}$. The second approach, in contrast, conceives of power as an effective and relational social reality (e.g., Redclift and Benton 1994; Clover 2002).

Within the framework of this paper, it is not possible to extensively elaborate on the differences between these two research approaches and how they rely on different visions of the root causes of the environmental problem and its possible solutions, of human beings and society. It suffices here to point to their divergent conceptions of power, of change and of the type of knowledge that is required for realising change.

\section{Research objective and design}

\subsection{Research objective}

The central question of our research is why some of the people who take action as a response to the environmental crisis choose individual behaviour change and others collective social action. On the basis of the literature briefly summarised above, one might hypothesise that 
these alternatives correspond with different visions of human beings and society and, more specifically, on the nature and role of power. In order to give a precise focus to our study, this question was applied to the case of climate change. Summarized, our research question is whether environmentally aware people think and/or experience that they have real power to contribute to a solution for climate change (or not) and what they think about how to exert this power.

\subsection{Research design: method, data collection and data analysis}

To explore this research question, we engaged in qualitative empirical research. As Rickinson (2001) has noted, qualitative research in this domain is relatively rare. The focus of the majority of previous studies has been on "the extent, rather than on the nature of [respondents'] environmental concern, attitudes and behaviours" (Rickinson 2001, 221). In order to study the latter, a qualitative research design was elaborated to allow us to delve more deeply into people's environmental convictions, experiences and actions.

The sample consisted of twelve young environmentally aware adults (age: 25-35 years) who are all highly educated, who are very concerned about climate change (according to themselves and people who know them) and who are environmentally committed in one way or the other. On the basis of snowball sampling we came into contact with a large group of such young 'environmentalists', amongst whom we chose twelve respondents on a theoretical basis (Baarda, De Goede, and Teunissen 2005; Babbie 2009). The goal of this purposive type of sampling was to select at least a certain variety of respondents (in terms of their ideological background, beliefs, and concrete engagements) that could give us a first idea of the range of possible answers to our research question (Baarda, De Goede, and Teunissen 2005; Denzin and Lincoln 2005). Concretely, the environmental engagements of our respondents varied from political activity to policy work, professional involvement in 
national environmental movements, voluntary work in local action groups and personal lifestyle changes. Their ideological positions ranged from green liberal to eco-socialist and eco-primitivist. All respondents were more or less part of what could be called the 'green scene' $^{3}$ (Horton 2006). Nine of them were women, three were men. They all lived in Antwerp, Ghent or Brussels, the three largest cities in Flanders, the northern part of Belgium.

Data collection consisted of semi-structured in-depth interviews of between one and two hours. The choice for this method of data collection was necessitated by the nature of the research questions. These focus on experiences and opinions, which cannot easily be studied through the observation of behaviour, but by directly questioning the respondents (SmithSebasto 2000; Baarda, De Goede, and Teunissen 2005). For an overview of the themes that were given as inputs, the interview schedule is added as an appendix (see appendix 1). The interview was structured in such a way as to steer the respondents as little as possible. Of course, interviewing never merely reveals people's consciousness, but inevitably also has the effect of creating it to a certain extent. An interview is "inextricably and unavoidably historically, politically, and contextually bound" (Fontana and Frey 2008, 115), however open and non-steering one tries to be. We are aware that, for example, formulating certain proposals and asking the respondents to react, has such an effect. We tried to counterbalance this influence on the respondents as much as possible by making the same suggestions to all respondents, and by putting the more concrete proposals at the end of the interview. However, making such proposals as such proved to be very important during the interviews as asking a respondent to react to a concrete proposal often revealed more of the respondent's experiences and ways of thinking than sticking to non-specific open questions.

The interviews were completely typed out and subdivided into text fragments. First, we started with open coding, in which each text fragment received one or more labels which covered the content as well as possible. Second, these codes were ordered to enable us to 
search for certain structures in the material. We did this with the help of the software package 'MindManager ${ }^{\circledR}$ ' which makes it possible to spatially order and visually structure the text material. In this process of axial coding, we several times added new labels on higher levels of abstraction, which finally led to a series of tree structures that gave a schematic overview of the research results. On the basis of these structures, a number of tentative hypotheses were formulated, which we elaborate upon in paragraph 4.

Within the limited scope of this study, it was not possible to fulfil all criteria of good qualitative research. For instance, we did not triangulate our data. Nevertheless, we increased the credibility, transferability, dependability and confirmability of our research by, e.g., choosing the data source that best fitted our research questions, using the method of purposeful sampling, recording the data digitally, making extensive reflective notes during the research process, giving a thick description of the research results, and engaging in member checking and limited peer debriefing (e.g., Reid and Gough 2000; Baarda, De Goede, and Teunissen 2005; Denzin and Lincoln 2005). Furthermore, we took the 'risk' of being confronted with discrepant information by searching for a maximum of variety in our limited sample (including 'extreme cases') ${ }^{4}$. Nevertheless, it should be clear that on the basis of this method, and given the specificity and relatively limited number of respondents, it is not possible to give definitive answers to the research question. Our primary goal was more modest: to explore the role of power in the choice for different types of environmental commitment and to formulate a number of directions for further research. The usefulness of such an exploratory approach is evident from the fact that many of our findings do not tally with the assumptions and expectations we had in the beginning, as will be explained more thoroughly in the next section. 


\section{Results and discussion}

In this part, we will discuss the research findings. In the limited scope of this article, it is not possible to provide an exhaustive overview of all significant elements present in the discourse of the respondents. Instead we will focus on five findings, which can possibly feed the current debate and trace new directions for future research. Firstly, we discuss the respondents' experiences of power(lessness). Secondly, we focus on what we would call 'strategy scepticism'. Thirdly, we reflect on the respondents' feelings of being conditioned, and their resistance to this. Fourthly, we discuss the observed 'gap' between the analysis respondents make and the strategy they propose. And, finally, we analyse another significant gap, that between what respondents say on a concrete and on a more abstract level.

\subsection{Powerlessness}

A first important observation is that while our original purpose was to map experiences of power and powerlessness, almost no text fragment could be labelled as an experience of power. The feelings that were mentioned most frequently are worry, indignation, pessimism, defeatism, and indeed, on top of the list, powerlessness ${ }^{5}$.

The respondents experienced this powerlessness with regard to several themes. Firstly, some referred to the huge scale, the long-term nature and complexity of the climate problem. These seem to have a paralysing effect, in that they render organising action against climate change quite difficult. Each action appears as negligible compared to the magnitude of the problem. As Laura ${ }^{6}$ stated when she made the comparison with her own actions for car-free Sundays: "Well, having car-free Sundays is of course something else than going against climate change. A car-free Sunday is something very concrete, but also very limited and easy to realise." 
Secondly, some respondents said that they felt incapable of comprehending the root causes of climate change. That made them feel powerless in the sense of not knowing against whom or what they had to act. Helga stated for instance:

I think it is also related to the fact that our economy is based on capitalism, and I think capitalism is detrimental to nature, and I think that.... but yeah, I don't know that for sure... I find that a difficult question also because I might not have read enough about these issues. I don't know all the details, I have to make sure that I'm not too... I'll think about it.

Thirdly, many respondents referred to the lack of strategic vision as an important cause of powerlessness. Several of them said they actually had "no strategy at all to tackle the issue" 7 , and pointed to this as "the biggest problem". Thus, Laura stated:

But I also think that the problem is actually that I don't really know what the right solution is, or what we should strive for. Well, I have a couple of ideas in my mind, but, to say, this is the right course, and let's now all turn this way, I don't really have this today. Because that would, I think, make it really very easy, and I also think that many people would do much more.

Sometimes this feeling appears to be related to a lack of knowledge of the range of possible strategic options. Sometimes it seems to result from the experience that nothing seems to work. Boris stated for example:

I really have difficulties with this, with which ways are still left over. What can we really do? Taking to the street has no effect. Taking legal steps against companies has no effect. Politics doesn't work. Lobbying politicians... has no effect, or too little.

Having arrived at this point, some respondents came up with 'extreme' strategies as the only possible alternative, although they turned out also to be sceptical about these in the end. Boris: 
Image that you found the CCC [an extreme left terrorist group in Belgium, operating in the 1980s], not composed of communists, but of ecologists, what will we do then? Placing bombs, and getting arrested the day after? Because we are heavily controlled, we can't do anything, everybody would see it. I've considered that, because you see indeed: nothing is happening here. That is powerlessness ... Then you think: we should get organised, and then we will make it all happen by ourselves. But yes... where to place a bomb? In Brussels? Whatever, that doesn't interest anyone.

Fourthly, almost all respondents mentioned the lack of a credible vision of an alternative as a crucial factor in experiencing powerlessness. Several respondents asked if they could skip this question, or said we should first ask other questions. Others kept on reflecting in silence. Many respondents felt that another type of society should be possible, but had to conclude that they were not capable of explaining what that society could look like. Laura stated for example:

One of the biggest problems is that I can't explain it very well. Actually, I do have such a kind of society in my mind, where this is all really possible, and it feels right. But I'm not able to explain it...

Several respondents concluded that in so far as they had an idea or a sense of an alternative, they still did not believe that it would ever be possible to realise it. Some even stated that they did not want to go on thinking about it for this very reason. Pauline: "Yes, I feel like... (strongly)... it is not that I don't have doubts , but I cannot but believe in it for myself... Because I don't think we will have another system within the next twenty years."

\subsection{Strategy scepticism}

A second finding is that it appeared impossible to draw a simple distinction between two forms of environmental commitment, as we set out to do. All respondents who were active on 
the collective social level were also engaged in individual behaviour change. The opposite was not the case. For many respondents, individual behaviour change was their only engagement. However, what came as a surprise is that almost none of the respondents said they believe that individual behaviour change could make a real contribution to tackle climate change. The arguments given for this kind of engagement were all of an ethical nature, they were about "doing the right thing". Boris argued for example: "For me, I wouldn't be able to live differently, but I know that in reality, it is zero, it doesn't matter at all." And Helga stated:

Maybe I do it in order to have a positive conscience or to earn my place in heaven [laughs]. I would feel badly if I were to carry on as I used to, but that doesn't mean that I think that I am making a real contribution.

This is a quite paradoxical observation: although "it doesn't help at all" ten out of twelve respondents invest serious efforts in buying organic food, saying no to the car, saving energy and so on. They seem to do things in which they do not really believe.

This surprising finding could have important consequences for pro-environmental behaviour research, especially if it would be confirmed in further research. Pro-environmental behaviour research studies the factors that make people change their individual behaviour. One of the most evident factors that is rarely taken into consideration, however, is the extent to which people actually believe that such a type of engagement, and the strategy on which it is based, is effective in the first place. Our research findings suggest that this point may be more important than one would think at first sight. In the case of environmentally aware people, at least, there is no lack of awareness of the nature and effects of the ecological problem, nor is there a lack of motivation to take action (for whatever social, psychological, cultural or other reasons one can imagine). All respondents described the climate problem as being very serious, and displayed a great motivation to take action. What seemed to be 
lacking, however, is the very belief that the currently dominant strategy of individual behaviour change is effective. A number of participants stated they increasingly tended to give up on this type of engagement, as they considered it ineffective. They said they used to be very strict on their individual behaviour in the past, but became less rigid in this because of their doubts about the usefulness of this type of action. Chantal stated for example:

And I'm also a little bit tired of always having to appeal to my own conscience, while, (...) every time I take the car, somehow I feel bad because of that ... But I don't find that's just, ... that people always have to take responsibility for the bad things. Because, ... uh, driving a car is bad, but as long as the government invests in roads instead of railways, there are no real alternatives, and nothing will really change...

As a conclusion, a tentative hypothesis we would like to formulate on the basis of this exploratory study is that an important reason why only relatively few people change their behaviour might not only be related to what is often referred to as 'climate scepticism' (Jones 2009), but also to what we would call 'strategy scepticism'.

\subsection{Conditioning and resistance}

A third finding is that most respondents were very critical towards people who actively try to convince others to change their individual behaviour, and towards educational actions promoting this (especially towards awareness raising campaigns that promote individual behaviour change in a "direct' ${ }^{8}$ way). Many respondents disapproved of the "blaming" or "paternalistic" character of these actions. Deborah argued for example:

And, then, I asked myself the question 'why don't I want to convince others' ... And then I come to the problem of culpabilisation, that you are making people feel individually responsible for the environmental crisis. And I don't agree with that ... 
Furthermore, several respondents criticised the fact that awareness raising campaigns, by focusing on individual behaviour change, tend to represent the climate problem as less serious than it actually is. Pauline stated for instance:

The big risk, of course, is that we all fall into the trap that ... we think that we are doing fine when we even once use the bicycle to go to the shop. Because that is what these campaigns are suggesting ... They sometimes even resemble a kind of collective easing of our conscience ... as if the goal is to give people a good feeling, to give the impression that the environmental movement and the government are taking the necessary steps to tackle climate change, when in fact, nothing is done ...

Many thought such awareness raising campaigns are even more 'questionable' to the extent that they are not only conducted by environmental movements or governments, but also by private companies. Helga for example was very critical of the Belgian electricity company L, which campaigned to convince people to save electricity:

I find that hypocritical. A big company like L, I don't know, I have never read they were so revolutionary in this regard, in saving energy on all levels. It remains a bad company of which I've heard many bad things, how they act towards consumers... It disturbs me when these companies act as if they are saints... I mean, when they promote something which seems good, all the while doing something else.

The intensity with which many respondents spoke was revealing. Martin stated for example that he is "sick" of these actions: "the companies just do what they want, and individuals are again asked to take responsibility".

As explained before, there is a recent tendency in environmental policy, but also in pro-environmental research and in the environmental movement, to increasingly focus on ways to steer people's behaviour 'directly' rather than to convince them by giving arguments 
and information. Our respondents reacted very strongly against this tendency, and criticised its paternalistic thrust. Eline stated for example: "It more and more looks like vulgar advertisement campaigns: images of sexy bimbos have to seduce people to eat vegetarian, well-known actresses are paid to promote organic food". Such reactions reveal something of how such attempts to steer behaviour 'directly' might be perceived by environmentally aware citizens, and confirm the criticisms that a number of authors have developed in a more theoretical fashion. These criticisms boil down to the observation that in such approaches, people are considered as objects to be conditioned rather than that they are taken seriously as subjects of change (Courtenay-Hall and Rogers 2002; Carlsson and Jensen 2006; Jensen and Schnack 2006).

The use of economic incentives is another way to directly steer people's behaviour. Like social marketing, it does not aim at educating people and giving them information, but contrarily, it attempts to appeal to a certain rationality, namely the instrumental reasoning of consumers. However, a comment by Chantal shows that people can also feel uncomfortable with this kind of steering. Chantal explained that since people have to pay for plastic bags in the supermarket, she feels the tendency in herself to use them more than she did before:

Yeah, in the past, I never used plastic bags ... I have to say that I do it more and more today ... In fact, I don't know why, but since they introduced this measure ... Since you have to pay for plastic bags, I changed my mind ... In fact, I don't know why ...

Is one of the reasons for Chantal's change of mind that what she did in the past out of autonomous moral considerations is now being 'steered' from above?

On the basis of our empirical findings, we cannot formulate general hypotheses that can explain the observed resistance against awareness raising campaigns. Further research and theoretical work is required to elaborate on this. As other authors (e.g., Luke 1997; Darier 
1999; Læssøe 2010) already suggested, Foucault's work on power and especially on governmentality might constitute a fruitful starting point here. In every social relation, there is power, and every power implies resistance, Michel Foucault (1994) explained. His notion of governmentality, which is about the "techniques and procedures for directing human behaviour" is of particular interest in attempting to understand what is at stake in individual behaviour change strategies (Rose, O’Malley, and Valverde 2006, 83). Governmentality involves the attempts to act on the desires and activities of others, aiming at "governing the forms of self-government, structuring and shaping the field of possible action of subjects" (Lemke 2002, 52). The specificity of this type of power, often conceived as a kind of ethical 'guidance', is that people do not merely obey, but seem to produce the government's objectives 'out of themselves', as it were. Subjects are supposed to 'govern their soul', consider their own life as an enterprise, and use techniques for self-improvement. It is no coincidence that new actors, such as policy bodies and non-governmental organisations, play a crucial role in such informal techniques of government that attempt to make individuals responsible for their "self-care" (Lemke 2002, 59). These techniques try to produce moral subjects, whose behaviour is supposed to generate beneficial effects on the level of the population as a whole (e.g. lowering the general level of carbon dioxide emissions). The statements of a number of our respondents seem to point to an intrinsic ambiguity of governmentality strategies: for these to be effective, forms of self-government must not be seen to be governed or steered. At the core of this ambiguity a space of resistance might develop that is oriented against attempts to steer individual behaviour. Although this is all formulated by way of hypothesis, what is obvious at least, is that measures like awareness raising campaigns can have a counterproductive effect on environmentally aware citizens.

\subsection{The 'gap' between analysis and strategy}


A fourth important observation is that there seems to be a lack of coherence in the responses of many respondents. Quite often, opinions were formulated that seem to be contradictory or at least at odds with each other. This might not surprise scholars who are familiar with this kind of qualitative research. However, what is striking is that we could observe some patterns which made these contradictions significant.

One case in point is the 'gap' between how respondents analyse the climate problem and the concrete solutions they propose. Almost all respondents point to the structural organisation of society as the root cause of climate change, stressing, for example, "the growth economy" or "capitalism". However, if one asks about solutions, the first, spontaneous answer one tends to get, is not the transformation of these structures, but individual behaviour change. For example, on the question "what are, according to her, the root causes of climate change" Eline answered: "Our capitalist economic system where everything turns around making profit... That's the big responsible .... And the democratic deficit, and the disappearance of ... the commons." When we asked her what should happen to tackle climate change, she answered: "Stopping with consuming so much?" How can we understand this apparent contradiction, especially given the observation that almost none of the respondents actually believed in the solutions they spontaneously first came up with during the interview? In what follows, we will discuss three characteristics of this observed gap between analysis and strategy that can help us understand what is at stake here.

To start with, it is remarkable that the respondents did not appear able to articulate strategies that fitted well with their own analysis. Many amongst them gave the impression that we were the first to ask them why they do what they do rather than something else. During the interview, they seemed to be confronted with the fact that they had not reflected a lot about their own choices. For example, when we asked Eva whether she thought the changes in her individual behaviour had an influence on the growth economy that she had 
identified as the root cause of climate change, she stated: "Uh, no idea...". And after a minute of silence: “Can I skip this question? No, I suppose?" Silence again. “Okay, I will try, but I will just think out loud, I don't have a clear idea about that yet ...” In the same line, it was striking that when we made suggestions about possible collective social actions, almost all respondents endorsed these proposals enthusiastically. When we proposed, as example, to organise a petition for a new public service for the insulation of old buildings, Eva stated immediately: "That's a good idea!" As long as we did not provide these suggestions, almost none of the respondents came up with this kind of idea themselves. This finding of course has methodological implications ${ }^{9}$, but also tells something about the respondents. One gets the impression that they are not capable of formulating different strategies and of reflecting on their comparative merits. Moreover, it appears that the solutions they think of can easily be influenced. To have a better understanding of what is at stake here, it is interesting to consider the four different types of action-oriented knowledge that Jensen (2004) distinguishes: (1) knowledge about the nature of the problem and its effects, (2) knowledge about root causes, (3) knowledge about strategies for change, and (4) knowledge about alternatives and visions. While it is remarkable that most respondents have quite adequate knowledge of the first type (the nature and effects of the climate problem), from the moment one considers the other three dimensions, namely root causes, strategies and visions, one observes a quasi linear decrease in the precision and sophistication of the responses. It was exactly these last three dimensions that triggered a strong feeling of powerlessness in the respondents (cfr. paragraph 4.1).

Secondly, it is remarkable that the respondents know the existing awareness raising campaigns quite well. As a response to the question what they do for the climate, most of them spontaneously list forms of individual behaviour change and when doing this, very often refer to existing campaigns. For example, Eva starts her answer (formulated in a remarkably imperative tense) as follows: "The things they say you should do: turn in saving light bulbs, 
use ecological detergent, use your bicycle or go by public transport, rebuild your house in an ecological way, use FSC-labelled wood, and so on." Even more striking is the fact that many respondents gave the impression that they assumed we were investigating whether they were doing well in their own behavioural choices. Especially their first answers seemed to be motivated by a concern for social desirability in this respect: "Yes, I use ecological detergent", "no, no, I almost never drive the car". One respondent sent us two text messages after the interview, because she remembered a few of her individual actions that she forgot to mention during the interview. Only when we clearly stated that they could interpret engagement in a broad way, from reading about the environmental issue to signing petitions and so on, the respondents seemed to feel relieved, stopped focussing on their own individual behaviour change, and even started to severely criticise this strategy, as was explained above.

Thirdly, it is noteworthy that, although several respondents stated that developments such as "the end of capitalism" are the only option to arrive at a final solution for climate change, none of them seemed to believe that this kind of radical social change is a feasible perspective today. In this sense, it is possible that the respondents have a certain knowledge about different strategies, but that they do not believe that real change is possible anyway. This could be a reason why they limit their engagement to "having no blood on their own hands", particularly because engaging oneself for structural change is always a gamble in a certain way. It is possible to struggle one's whole life for such change without any tangible result. One of the advantages of individual behaviour change is that you can at least always say your actions have borne some results, however limited these are. As Deborah stated:

It sounds maybe very pathetic, but I also want to be able to say at the end of my life, look, I have done my bit for this world, and I didn't only talk, I also tried to reduce my ecological footprint. I find it important to have the possibility to make such a positive balance at the end ... Because if you only look 
to structures, and for example, you don't succeed ... then I don't think that you can really make a positive balance at the end.

This suggests that there perhaps exists an even stronger connection between people's engagements and their opinions and experiences of power(lessness) than suggested above. Maybe people do not choose the strategy that seems most powerful or effective, but just feel totally powerless when confronted with the real causes of the problem? The choice for individual behaviour change might not then be a genuine strategy for change, but rather an attempt to be compromised as little as possible by a system that they think they cannot change anyway. Laura stated for example: “I think I feel more at ease because I don't have to feel guilty ... I don't think that I really make a contribution, but neither do I do something really wrong or bad." A little bit later, she added: "In fact, I just would like to leave behind that whole system that is so polluting and burdened ... and corrupt". In this sense, individual behaviour change becomes a moral matter of a particular kind: the respondents do it to have "a good conscience", "to earn their heaven" or to have "no feelings of guilt".

Nevertheless, most respondents seemed to be convinced that on certain moments "times may change". Some stated, for example, that with an increase of natural disasters people will start raising their voices. Steve explained:

I hope for a series of events, for example the mudflows in Limburg, or erosion if it rains too much. They know the cause perfectly well..., and solutions exist ... I hope that some disasters will take place, I mean, 'disasters' is not the right word ... events that will make people take action.

And Chantal stated: "For example, on a certain moment we will be out of oil, or any other ... it is to say, people will not just put up with all that ..." Remarkably, if "times will change", what the respondents see happening is not only, or not in the first place, a greater engagement 
in individual behaviour change, but "a raising of voices". In this, they often refer to how social change happened in the past. Shane stated for example:

But if the crisis really takes on big proportions, I think people will raise their voices and take to the streets ... I'm thinking for example about the workers movement, that really started from below, ... And I believe in something similar with respect to climate change, from the moment that people see what is at stake.

\subsection{Consistency and common sense}

A last important finding has to do with another lack of coherence we observed in the stories of the respondents, namely between what respondents stated on a more abstract and on a more concrete level. This was most remarkable when respondents were asked questions about whether they believed in a conflict or collaboration model to realise change. For example, in the beginning Chantal said:

I think it is not so smart to make a story of 'us against them'. Because I think companies should just be sensitised and they have to understand that it can be interesting from an economic point of view to produce environmentally friendly stuff.

However, a little later, she stated:

Oh, E [a large energy company in Belgium], I find really horrific. The way they act as if they provide green electricity. They are just profiteers. Companies like E, I find them terrible. They enslave us by their monopoly position... Yeah, if they would produce more green electricity they would give us more choice. But instead, they opt for as much profit as possible.

This lack of coherence in the answer of Chantal is no exception. Almost all respondents advocated collaboration in general, theoretical terms, but when asked about concrete situations, collaboration was often strongly rejected in favour of a more conflict- 
oriented approach. This difference between abstract and concrete answers has its counterpart in the difference between more experiential and more cognitive convictions. Shane explained, for example: "Instinctively, I find it very difficult that $\mathrm{N}$ [an environmental organisation in Flanders] is sponsored by E", but a few minutes later she stated that she "thinks" it is very important to work together with companies and that she does not "believe" in "an anticulture".

The more abstract answers that were given by the respondents seemed to be more in conformity with the dominant discourse : "yes, of course I am in favour of collaboration", "no, of course not, I am against extremes", "yes, everyone hand in hand" and we certainly prefer "win-win-situations". But these positions often clashed with what they proposed in more concrete situations: then the environmental movement should suddenly be much more "aggressive", "radical" and "ready for battle". These concrete judgments were often expressed with much more power and emotion. When we confronted the respondents with this observation and continued to inquire along these lines, many became confused or openly started to contradict themselves. It often happened that respondents changed their mind during the interview, and/or made explicit efforts to make their own story more coherent than it at first appeared to be. Some respondents did this even explicitly. We asked for example to Chantal: "But didn't you tell something else in the beginning? There you seemed to say that..." And she answered: "I evolved (laughs). Yes, no, because I have to think about it now, I have to reflect much more within myself, and it is quite difficult to say that..."

The work of Antonio Gramsci (1971) can shed an interesting light on such incoherencies. Gramsci paid a lot of attention to the 'spontaneous' consciousness of people, which he called 'common sense'. This includes 'diffuse, uncoordinated features of a general form of thought common to a particular period and a particular popular environment" (Gramsci 1971, 330). According to him, the common sense is fragmentary, incoherent and 
inconsequential, but it can develop into "a healthy nucleus of good sense" when it is made more coherent (328). Furthermore, Gramsci (1971) explains there can be a tension between what people do in practice and what they think theoretically. In a certain way, they can have two consciousnesses: one which is implicit in their activity but which they often cannot easily articulate, and one which they acquired by absorbing existing discourses.

These reflections can illuminate some of the observations we made above about the respondents' 'contradictory consciousness'. In particular, there seems to be a discrepancy between the abstract norms of collaboration and dialogue which the respondents upheld and which can be said to be part of the dominant discourse, and their concrete ideas about struggle and resistance that are not yet articulated on such an abstract level. What is remarkable, however, is that most respondents are not just randomly chosen individuals, but people with a relatively highly developed environmental consciousness. In this sense, they are 'intellectuals' themselves in the general meaning Gramsci gave to this term. According to Gramsci (1971), all people who are engaged in the formulation and distribution of ideas amongst the mass of people are intellectuals, and consequently, all are involved in ideological struggle. This means that they take part in the (often implicit) struggle about the different directions in which people's common sense can be led, or in other words, in which their common sense can be made more coherent. However, as the research findings suggested, most of the respondents seemed not to be aware of this struggle, let alone that they play a fully self-conscious role in it. As such, the lack of coherence in the answers of the respondents possibly says something about the extent to which the current environmental movement has well-articulated analyses, strategies and visions at its disposal.

\section{Conclusion}


As this article is based on exploratory research, we cannot draw definite conclusions, but we can develop some hypotheses, and sharpen our concepts and questions. The least we can say is that our assumption about the role of power and powerlessness seems to have been a useful starting point. In a paradoxical way, our research suggests that most respondents do not engage in individual behaviour change because they consider it to be effective or because it gives them the possibility to exert power. Quite the contrary, many experience that they have no power at all, or at least lack the power to engage in the collective social actions which they believe are really necessary. As a result, most respondents do something that actually is within their reach, but which they do not really believe to be effective. As such, the core of the problem indeed seems to be a question of power. It presents itself as a paradox: the starting point seems to be an experience of powerlessness, which follows from what we have called 'strategy scepticism', directed against the dominant strategy of individual behaviour change, and from a lack of credible alternatives.

Consequently, this finding suggests that closing the 'gap' between knowledge and action does not in the first place - at least not in the case of environmentally aware citizens require a further raising of people's knowledge of the environmental problem as such. What seems to be needed, is knowledge of root causes, visions on alternatives and especially strategies to reach these. By leaping too directly from knowledge of the nature and effects of the environmental problem to the level of solutions, the individual behaviour change approach risks sidestepping not only the human-societal context within which the problem arose, but also the possibility for people to engage in strategic reflection themselves and to draw their own conclusions on the kind of actions required. In other words, it risks sidestepping the possibility for people to be really em 'power'ed citizens and potential subjects of change.

As a conclusion, one can state that, whereas there is a quite clear distinction between 'individual behaviour change' and 'collective social action' studies in a lot of policy and 
academic literature, the distinction is maybe not so clear-cut in the minds of ecologically concerned citizens. Whereas almost all respondents were (also) involved in individual behaviour change, most seemed to prefer collective social action as a strategy towards change, even if they did not put this strategy into practice. One of the most important barriers to undertaking the latter seems to be that the dominant discourse does not provide them with the conceptual tools needed for engaging in these kinds of action. More attention to the 'actionoriented' domains of knowledge (knowledge about root causes, strategy and alternatives) might compensate for this.

Concerning this, it is important to acknowledge that there exists a fundamental difference between strictly physical knowledge about climate change and action-oriented domains. The latter can never be as exact as the first. If one speaks about analysis, strategies and alternatives, one definitively enters onto ideological terrain. On the basis of Gramsci's work we have shown that 'common sense' is a fragmented and incoherent collection of all sorts of ideas and influences, and that ideological struggle has to do with making this common sense more coherent in one way or another. In a certain way, environmental researchers and/or educators are also involved in this ideological struggle, whether they want it or not. Their position is not easy. On the one hand, they cannot claim to make 'objective' judgments. On the other hand, they cannot neglect this terrain either, as they then risk allowing for it to be occupied by movements, governments or companies that also have other interests than the 'common good'. Maybe the task of researchers and/or educators can be to try to make the range of possible analyses, visions and strategic options visible and to make their assumptions, effects and implications explicit. Hereby, it is of central importance to get to the abstract level of the principles underlying these, and to be conscious of the fact that one thus enters an ideological battlefield. One of their contributions could even be to disclose the very ideological character of the debate as such. 


\section{Notes}

${ }^{1}$ The first was the slogan of a Greenpeace campaign to stimulate people to choose a renewable energy provider (Greenpeace 2009), the second was the main slogan of an action organized by a couple of thousand activists against the climate summit in Copenhagen in December 2009 (ClimateJusticeAction 2009).

${ }^{2}$ In its list of important barriers for pro-environmental behaviour, the DEFRA report $(2008,35)$ mentions the following examples: (1) "Scepticism around the climate change debate and distrust of both government and industry. For example, about a quarter don't believe their behaviour contributes to climate change." (2) "Disempowerment, as there is a disconnection between the size of the problem (Global Climate Change) and the individual's contribution (e.g. turning off lights) and a sense that individuals cannot make a difference. About one third said it was not worth Britain acting, as other countries would cancel its actions out. More than half claimed if government did more, they would too". As such, experiences of powerlessness are psychologised. They are not taken seriously, but reduced to a feeling, a false impression, that has to be taken away. Instead of understanding the choice not to engage in pro-environmental behaviour as being based on an analysis of the problem and on a strategic judgement, it is approached as a behavioural problem. Authors such as Redclift \& Benton (1994, 7-8) sharply reply to this with statements such as: "One of the most important insights which the social scientist can offer in the environmental debate is that the eminently rational appeals on the part of environmentalists for 'us' to change our attitudes, or lifestyles, so as to advance a general 'human interest' are liable to be ineffective. This is not because (or primarily because) 'we' are irrational, but because the power to make a significant difference, one way or the other, to global, or even local environmental change is immensely unevenly distributed."

${ }^{3}$ The fact that all respondents were more or less in the 'green scene' (Horton 2006), is one of the limiting factors of our sampling. It is surely possible that a sample of, say, governmental officials, with no connection to this green scene, would give different results.

${ }^{4}$ With 'extreme cases' we mean people who adopt a quite radical ideological position and/or go quite far in their own environmental commitment. For example, a few respondents went amazingly far in changing their individual behaviour: they took a shower only once a week and only with cold water, they stopped visiting their parents who serve non-organic food for dinner or they lived without heating even during winter months. Others were so committed to organising actions, to demonstrating or to giving lectures that their personal lives and 
health suffered from it. Ideologically, some respondents were very liberal, while others were eco-primitivist or eco-communist.

${ }^{5}$ It is important to mention that respondents knew that the study was about their commitments and motivations with regard to climate change, but not that 'power' and 'powerlessness' were crucial concepts in our approach. Therefore, it is not the case that they mentioned these terms so often because they would have known this was our core question.

6 We have translated the Dutch interviews into English, trying to remain as close as possible to the original, spoken language. The names of the respondents, corporations and organisations have been modified, for reasons of anonymity.

${ }^{7}$ If we put a word or sentence in double quotation marks, it means that we quote a respondent directly.

${ }^{8}$ With the term 'direct' we refer here to the idea of Tim Jackson (2005, vi) that we quoted in the introduction, namely "the need for policy to [...] attempt to affect individual behaviours (and behavioural antecedents) directly". Concretely, this means using role models, social pressure or connoting the desired behaviour to positive feelings of freedom, friendship or sex, as is also done in the advertisement industry.

\section{Notes on contributors}

Anneleen Kenis has a master in psychology and in sustainable development and human ecology. She is currently working as a doctoral researcher at the Department of Earth and Environmental Sciences, KULeuven, Belgium. Her research interests include sustainable consumption, ecological citizenship, education, movement building, democracy and politicisation.

Erik Mathijs is Professor of Agricultural and Resource Economics at the Department of Earth and Environmental Sciences, KULeuven, Belgium. His current research focus is on sustainable agriculture and food production and consumption, social innovation and sustainability evaluation. 


\section{References}

Baarda, B., M. De Goede, and J. Teunissen. 2005. Basisboek kwalitatief onderzoek: Handleiding voor het opzetten en uitvoeren van kwalitatief onderzoek. Groningen/Houten: Wolters-Noordhoff.

Babbie, E. 2009. The practice of social research. Belmont: Wadsworth.

Bamberg, S., and G. Möser. 2007. Twenty years after Hines, Hungerford, and Tomera: A new meta-analysis of psycho-social determinants of pro-environmental behaviour. Journal of Environmental Psychology 27: 14-25.

Carlsson, M., and B.B. Jensen. 2006. Encouraging environmental citizenship: The roles and challenges for schools. In Environmental citizenship, ed. A. Dobson and D. Bell, 237262. London: MIT Press.

Chawla, L., and D.F. Cushing. 2007. Education for strategic environmental behavior. Environmental Education Research 13, no. 4: 437-452.

Clair, R. 2003. Words for the world: Creating critical environmental literacy for adults. New Directions for Adult and Continuing Education 99: 69-78.

ClimateJusticeAction. Reclaim power! Push for climate justice! http://www.climate-justiceaction.org/news/2009/08/14/december-16th-18th/.

Clover, D. 2002. Traversing the gap: concientización, educative-activism in environmental adult education. Environmental Education Research 8, no. 3: 315-323.

Clover, D. 2003. Environmental adult education: Critique and creativity in a globalizing world. New Directions for Adult and Continuing Education 99: 5-16.

Clover, D. 2006. Policy development, theory and practice in environmental adult education: reflections on the learning for environmental action programme from 1995 to the present. Convergence 39, no. 4: 51-54. 
Courtenay-Hall, P., and L. Rogers. 2002. Gaps in mind: problems in environmental knowledge-behaviour modelling research. Environmental Education Research 8, no. 3: 283-297.

Darier, E. 1999. Foucault and the environment: An introduction. In Discourses of the environment, ed. E. Darier, 1-34. Oxford: Blackwell Publishers.

DEFRA. 2008. A framework for pro-environmental behaviours. London: DEFRA.

Denzin, N. K., and Y. S. Lincoln, eds. 2005. The sage handbook of qualitative research. London: Sage Publications.

Doherty, B., Alexandra P., and D. Wall. 2003. 'The preferred way of doing things': The British direct action movement. Parliamentary Affairs Volume, 564: 669-686.

Fontana, A., and J.H. Frey. 2008. The interview: from neutral stance to political involvement. In Collecting and interpreting qualitative materials, ed. N.K. Denzin and Y.S. Lincoln, 115-159. London: Sage Publications.

Foucault, M. 1994. Power. London: Penguin Books.

Gramsci, A. 1971. Selections from the prison notebooks. Londen: Lawrence \& Wishart.

Greenpeace. You've got the power to choose. http://www.youvegotthepower.be.

Griggs, S., and D. Howarth. 2000. New environmental movements and direct action protest: the campaign against Manchester Airport's second runaway. In Discourse theory and political analysis. Identities, hegemonies and social change, ed. D. Howarth, A.J. Norval and Y. Stavrakakis, 52-69. Manchester: University Press.

Heimlich, J.E., and M.N. Ardoin. 2008. Understanding behavior to understand behavior change: a literature review. Environmental Education Research 14, no. 3: 215 - 237.

Horton, D. 2006. Demonstrating environmental citizenship? A study of everyday life among green activists. In Environmental citizenship, ed. A. Dobson and D. Bell, 127-150. London: The MIT Press. 
Jackson, T. 2005. Motivating sustainable consumption. A review of evidence on consumer behaviour and behavioural change. Surrey: SDRN.

Jensen, B.B. 2002. Knowledge, action and pro-environmental Behaviour. Environmental Education Research 8, no. 3: 325-334.

Jensen, B.B. 2004. Environmental and health education viewed from an action-oriented perspective: a case from Denmark. Journal of Curriculum Studies 36, no. 4: 405 - 425.

Jensen, B.B., and K. Schnack. 2006. The action competence approach in environmental education. Environmental Education Research 12, no. 3-4: 471-486.

Jones, P.T. 2009. Klimaatcrisis. Het failliet van het klimaatscepticisme. Antwerpen: Luster.

Kapoor, D. 2003. Environmental popular education and indigenous social movements in India. New Directions for Adult and Continuing Education 99: 47-58.

Kollmuss, A., and J. Agyeman. 2002. Mind the gap: why do people act environmentally and what are the barriers to pro-environmental behavior? Environmental Education Research 8, no. 3: 239-260.

Læssøe, J. 2010. Education for sustainable development, participation and socio-cultural change. Environmental Education Research 16, no. 1: 39-57.

Lemke, T. 2002. Foucault, governmentality, and critique. Rethinking Marxism 14, no. 3: 4964.

Luke, T.W. 1997. The (un)wise (ab)use of nature: Environmentalism as globalized consumerism? Paper presented at International Studies Association, March 18-22, in Toronto.

Malone, K. 2006. Environmental education researchers as environmental activists. Environmental Education Research 12, no. 3-4: 375-389.

McKenzie-Mohr, D., and W. Smith. 1999. Fostering sustainable behavior: an introduction to community-based social marketing. Gabriola Island: New Society Publishers. 
Redclift, M., and T. Benton, eds. 1994. Social theory and the global environment. London: Routledge.

Reid, A., and S. Gough. 2000. Guidelines for reporting qualitative research: what are the alternatives? Environmental Education Research 6, no. 1: 59-91.

Rickinson, M. 2001. Learners and learning in environmental education: a critical review of the evidence. Environmental Education Research 7, no. 3: 208-320.

Rootes, C. 2009. Environmental protests, local campaigns and the environmental movement in England. Paper presented at European Consortium for Political Research, April 1419, in Lisbon.

Rose, N., P. O'Malley, and M. Valverde. 2006. Governmentality. Annual Review of Law and Social Science 2: 83-104.

Smith-Sebasto, N. J. 2000. Potential guidelines for conducting and reporting environmental education research: qualitative methods of inquiry. Environmental Education Research 6, no. 1: 9-26.

Stevenson, G., and B. Keehn. 2006. I will if you will. Towards sustainable consumption. London: SDC/NCC.

Wall, D. 1999. Earth First! and the anti-roads movement. London: Routledge. 